\title{
The Preliminary Research of Guojuanyan Debris Flow Characteristics and Prevention Measures Post-Earthquake
}

\author{
Shun Yang ${ }^{1, a}$, Hai Huang ${ }^{1, b}$, Huali Pan ${ }^{2,{ }^{*}, \mathrm{c}}$, Jiankang Liu ${ }^{1, \mathrm{~d}}$ \\ ${ }^{1}$ Technical Center for Geological Hazard Prevention and Control, CGS, Chengdu 611734, \\ China;Institute of Exploration Technology, CAGS, Chengdu 611734, China \\ ${ }^{2}$ Key Laboratory of Mountain Surface Process and Hazards, CAS, Chengdu 610041, China, \\ Institute of Mountain Hazards and Environment, CAS, Chengdu 610041, China \\ ayangsh@cgiet.com, ${ }^{b}$ hhai84@ 163.com,,'cphl@imde.ac.cn, ${ }^{\mathrm{d}} \mathrm{ljk} @$ coiet.com
}

Key words: debris flow, formation conditions, activity characteristics, prevention measures

Abstract.Sichuan Basin come into rainy season entirely in the early July, 2013, Dujiangyan city of Wenchuan strong earthquake district encountered a hundred-year rainstorm process, which raised numerous Secondary Mountain hazards as collapse, landslide and debris flow etc. Generally, high frequency of debris flowresult in the loss of life and property in disaster region which delay the rescue after disaster happened and local reconstruction. On July, $9^{\text {th }}, 2013$, a largest debris flow occurred in Guojuanyan gully (abbreviation GJY below) of Shenxigou watershed, Dujiangyanpost-earthquake (hereinafter referred to as "7.9"debris flow). On the basis of field survey and analysis of the formation factors and characteristics of this debris flow, as well as the debris flow activity after Wenchuan earthquake and its development tendency are studied. The research indicated that GJY have transferred into debris flow gully from flood ravine after earthquake effect.The burst frequency and volume scale shown an increasing trend, GJY debris flow enter high frequency period in the next dozens of years. Therefore, it posed debris flow prevention advices on mountain hazard for GJY and the whole Shenxigou region.

\section{Introduction}

2008 5.12 Wenchuan Earthquake, which not only brought in serous loss of live and properties, but also changed violently of geo-environment of Mt LongmenFault, resulted debris flow activity even more frequently.Debris flow hazard will take a big menace to hazard region in a long run. Currently, numerous debris flow events caused by short during rainstormhave resulted in many local people died[1] and brought lots of new questions on reconstruction.

Based on detailedfield survey of GJY debris flow in July $9^{\text {th }}$, 2013, the research analyzed the debris flow formation condition and hazard characteristics, calculated the debris flow dynamic parameters and the gully's development tendency which would provide theory base of debris flow forecast, early warning and debris flow prevention for west mountain debris flow areas.

\section{The Outline of GJY Gully Watershed}

\section{Regional Geological Condition}

GJY gully, which site in Shenxi village, Hongkou town of Dujiangyan city, is a small sub gully on the left bank of Shenxi gully. Recent year, the debris flow activity increased frequently. From Google earth, it can be seen the surface of GJY gully changed largely[2], as Fig.1. The area of GJY gully is $0.15 \mathrm{~km}^{2}$, the gully length is $0.55 \mathrm{~km}$, there is none of sub gully, the highest point is $1200 \mathrm{~m}$ and the outlet of gully is $970 \mathrm{~m}$, the angle of slope is from 15 degree to 45 degree. 


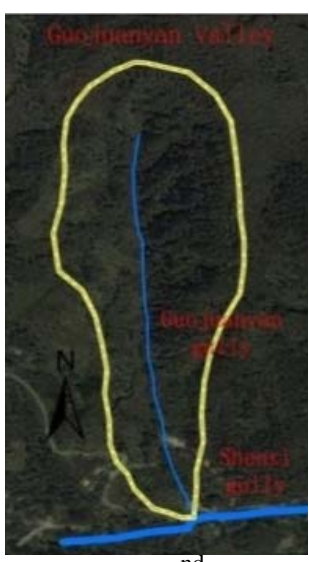

(a) July $22^{\text {nd }} 2005$

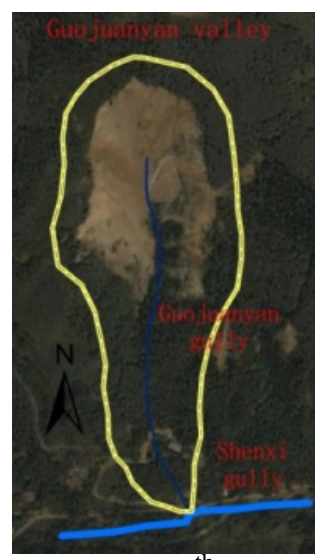

(b) June $6^{\text {th }} 2008$

Fig.1.The change before and after the Wenchuan Earthquake (From Google Earth)

The region is in the middle of Mt LongmenFault, the loosen solid materials distributed on the cracked land surface widely, the gully section present ' $V$ ' shape which show deep cutting in this region. Another, Shenxi gully watershed belong to the humid subtropical climate zone, the annual rainfall distribution was uneven and it mainly concentrated between June and July, through statistics, the mean annualprecipitation is $1221.0 \mathrm{~mm}$. The main stratum is the Quaternary grave, Triassicquartzsandstone, Devonian system's dolomitelimestone and Sinian system's volcanic rock et al[3]. Meanwhile, the local soil is deposit and alluvium, the vegetation coverage is nearly 50\% post-earthquake which distributed ornamental plants as Cedar, Common Camptotheca Fruit, Juglandaceae et al, Kiwifruit and Mangnoliaofficinalis also planted widely by local people.

\section{Debris Flow Hazard}

Through field survey, it found that none of the debris flow happened before Wenchuan Earthquake, there were just small scale floods in every rainy season, which belong to high frequent flood gully. While after Wenchuan Earthquake, numerous loosen solid materials as collapses and landslides to form different scale debris flows under heavy rainfall process, the flood gully have changed to debris flow gully gradually.

From July, 2013, the intersection region of Sichuan Basin and Mt Longmen entered into the high peak of precipitation, especially the rainfall process from July $8^{\text {th }}$ to $12^{\text {th }}$, the precipitation area was overlapped by '5.12' Wenchuan Earthquake and ' 4.20 ' Lushan Earthquake. According to meteorological observation from Xingfu town of Dujiangyan, the total rainfall of those days reached 1129.0mm which beyond the average annual rainfall amount of Dujinagyancity; it is happened once in a hundred year[4]. With continuous heavy rainfall, hazard as flood, debris flow, landslide and collapse broken out one by one, through statistics, more than 300 geohazard points appeared after this rainfall process. GJY gully also happened one of the most serious hazard in $9^{\text {th }}$, July, which brushed the country road between Hongkou and Longchi, buried 2 farm building and drainage canal, and even destroyed part of debris flow monitoring devices constructed by experiment group.

\section{Cause Analysis andCharacteristics of GJY Debris Flow}

\section{Debris Flow Formation Condition}

\section{GeomorphicCondition}

Shenxiwatershed is in the east part of Mt LongmenFault which is the strong tectonic section, because of the small watershed and large slope angle make the cross section show a typical ' $\mathrm{V}$ ' style, it is belong to alpine valley region. Through field observation and GIS, it is found that wide and steep surface above the check dam in the GJY gully, the section's angle of slope reached $400 \%$, it is favor for surface water's confluence rapidly, which provided potential energy condition for debris flow. While the section between check dam and GJYBridge, it is a long but narrow gully, show deep' $V$ ' style, the average angle of slope is 230\%o, which is useful for debris flow's movement. The downstream of GJY gully is the constructed debris flow drainage canal, the average 
angle of slope is 200\%o, a certain scale debris flow often deposited on the country road and in the Shenxi gully. The steep slope provided useful topographical condition, see as Fig. 2.

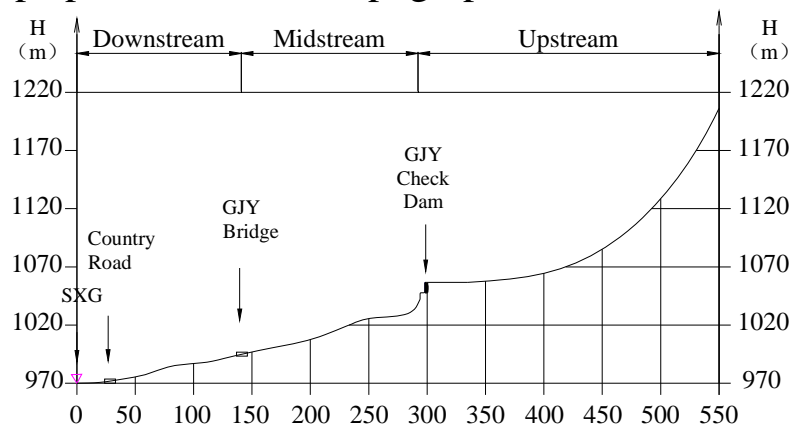

Fig. 2 The longitudinal profile of GJY gully

\section{Precipitation Process}

Through analysis, it could attain that the antecedent rainfall and daily heavy rainstorm resulted in the GJY'7.9' debris flow. According to rain gauge observation in the watershed, there were 16 days had rainfall record before $8^{\text {th }}$, July, the antecedent accumulative rainfall reached $264.5 \mathrm{~mm}$, even $2^{\text {nd }}$ and $4^{\text {th }}$, July, 2013 was $42.0 \mathrm{~mm}$ and $62.5 \mathrm{~mm}$ respectively. With the infiltration of the antecedent rainfall, a small scale debris flow rose by continuous rainfall amount of $47.5 \mathrm{~mm}$ in the evening of $7^{\text {th }}$, July. From then on, GJY gully suffered heavy rainstorm continuously from $8^{\text {th }}$ to $10^{\text {th }}$, July, the daily rainfall amount reached $176.0 \mathrm{~mm}, 244.5 \mathrm{~mm}$ and $162.5 \mathrm{~mm}$ respectively, which exceed the average daily precipitation amount of 130mm in Hongkou village, Dujiangyan[5].

The accumulative rainfall between $7^{\text {th }}$ and $11^{\text {th }}$, July was $647.0 \mathrm{~mm}$, the frequency belong to once in a hundred years. The antecedent rainfall process curve from 21:10 of $8^{\text {th }}$ to $14: 10$ of $9^{\text {th }}$ was shown as Fig.3. Significantly, the antecedent rainfall made water content increase sharply which result in pore water pressure rising and soil strength is losing. Together with field HD camera monitoring and rainfall process, it could be determined that GJY gully have broken out 3 debris flows at 21:30 in $8^{\text {th }}, 3: 10$ and 7:30 in $9^{\text {th }}$ respectively, but the lasting time of each debris flow was short, it was about 40 min each, the minute precipitation process was shown as Fig. 4.

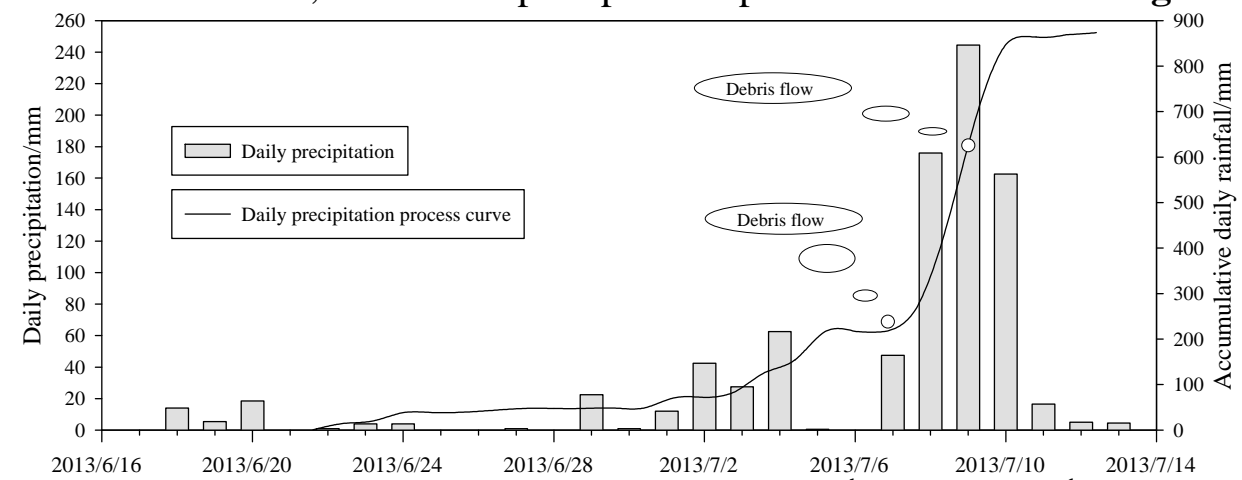

Fig.3 The daily rainfall process of GJY gully between $17^{\text {th }}$, June and $13^{\text {rd }}$, July, 2013

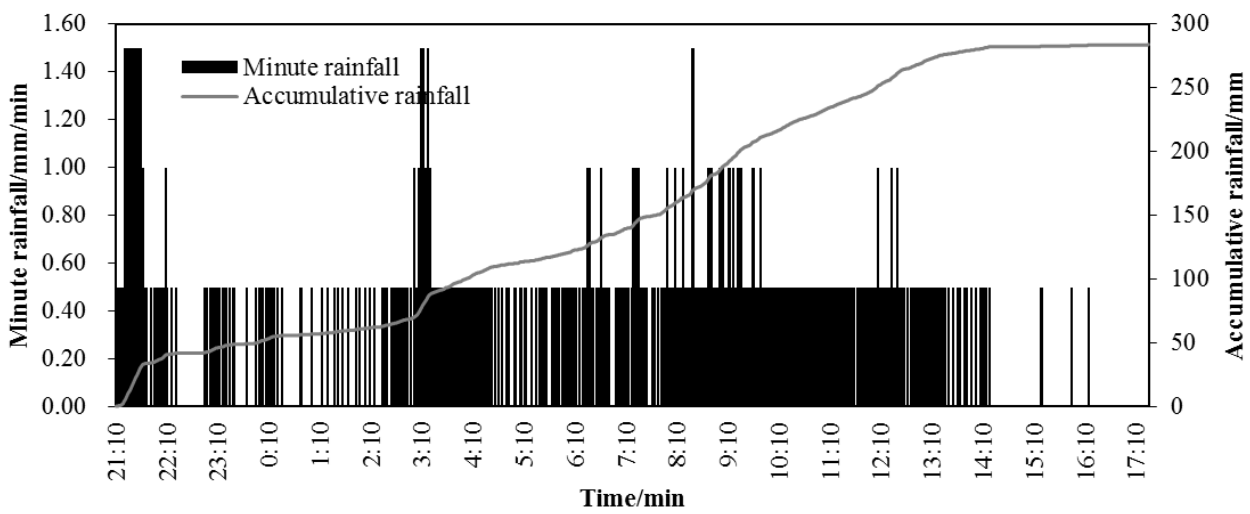

Fig.4 The minute precipitation process of GJY gully between $8^{\text {th }}$ and $9^{\text {th }}$, July, 2013 


\section{Loosen Solid Materials}

Wenchuan-YinxiuFault is run through ShenxiValley.Wenchuan Earthquake caused cracks along north-west direction which formed a $300 \mathrm{~km}$ earthquake rupture zone.Meanwhile, the strong shock and frequently after-shock make numerous mountain hazards as rock fall, landslide in these areas[6]. Those rocks mass not only made mountain surface in piece, but also accumulated abundant of loosen solid materials which provided the surplus solid condition to form debris flow[7]. Actually, the source area of GJY gully (above the check dam) collapsed every year, formed abundant of loosen solid materials on the surface of gully and slope which supply enough solid materials for debris flow.

\section{Human Activities and Debris Flow Hazard}

The flat gully mouth of GJY gully is one of the mainly local residential areas. Due to the special geomorphological environment, none of farm land was in the whole watershed and the most land wasplanted by economical crops as Magnolia officinalisRehd. etWils,Actinidiachinensisets.

Before Wenchuan Earthquake,GJYwas just a common flood gully and nearly none of disaster menace suffered to local people, while the earthquake hit strongly the flat fan, most of the local buildings collapsed which resulted in heavy loss of people's life and properties, with the help of local government, many people have been transferred to safe place inTongmakan town, therefore, the left ones who refused to move to Tongmakan were the mainly potential affected victims. Thus, in the first three years after Wenchuan Earthquake, local department of ministry of land and resources have built a check dam before the rainy season in 2011, meanwhile, a $100 \mathrm{~m}$ drainage canal was constructed by local residents of the left bank, which take a great defense for debris flow in the next two years. However, without evaluating the capacity of debris flow scale and avoid destroying the building on the left bank, local residents made a large angle of drainage canal mouth into Shenxi gully. Therefore, because of the small scale debris flow in the first two years which did not cause hazard, but in the third year, the large scale and high speed velocity of '7.9' debris flow rushed out of the high curve and buried the left building as high as $4.5 \mathrm{~m}$, see Fig.5.

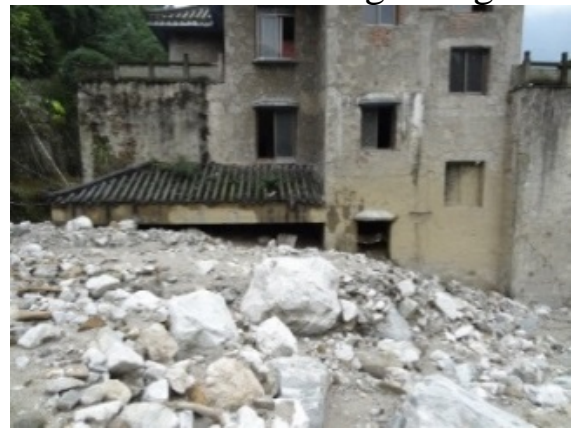

Fig.5 The buried house on the left bank of gully mouth

\section{Debris Flow Characteristics}

\section{Supply Characteristics}

The formation, transfer and deposition area of GJY gully are obviously, which is belong to typical gully debris flow, especially the area above the check dam of GJY gully, abundant of loosen solid materials as landslide and rock fall distributed on the surface of gully and slope foot; while in the transfer part between check dam and gully outlet, numerous loosen solid materials which include landslide mass, human garbagy et al distributed on the both bank and in the gully, thus, the blockage is very serious. Therefore, the mainly solid materials are composed of landslide mass, collapse and construction garbage in the gully.

According to field survey, the debris flow present melangedeposition characteristics and a significant reverse diameter phenomenon which helped to evaluate the debris flow of this gully belongs to viscous debris flow. Meanwhile, through experiment of the soil samples, it attained the debris flow density is $2.05 \mathrm{~g} / \mathrm{cm}^{3}$, the viscous particles is $4.23 \%$. Else while, on considering the relationship between the two important particles diameter and debris flow density of debris flow deposition, and together with the particle distribution curve of GJY gully (see Fig.6), which could calculate the density is $2.10 \mathrm{~g} / \mathrm{cm}^{3}$, thus, the two value are very closing which could be defined as 
the actual GJY gully density.

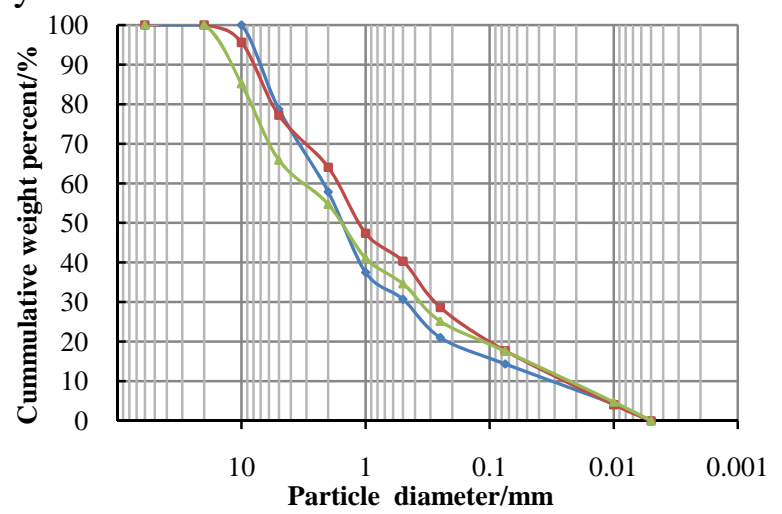

Fig.6The particle distribution curve of '7.9’ debris deposit

\section{Debris Flow Dynamical Features}

Through field survey after this debris flow event, the mud line, the max debris width, the average debris flow depth et al were investigated detailed, as well as the angle of gully and slope, the max debris flow cross-section, the statistics results see Table 1, the gully cross-section, see Fig.7. Else while, it could get that GJY gully is becoming high frequency viscous debris flow gully in recent year, thus, through available viscous debris flow formula[8] and viscous debris flow average velocity calculation equation[9], it can calculate the flow velocity and discharge respectively, the results between investigation and calculation are very close, see Table 2.

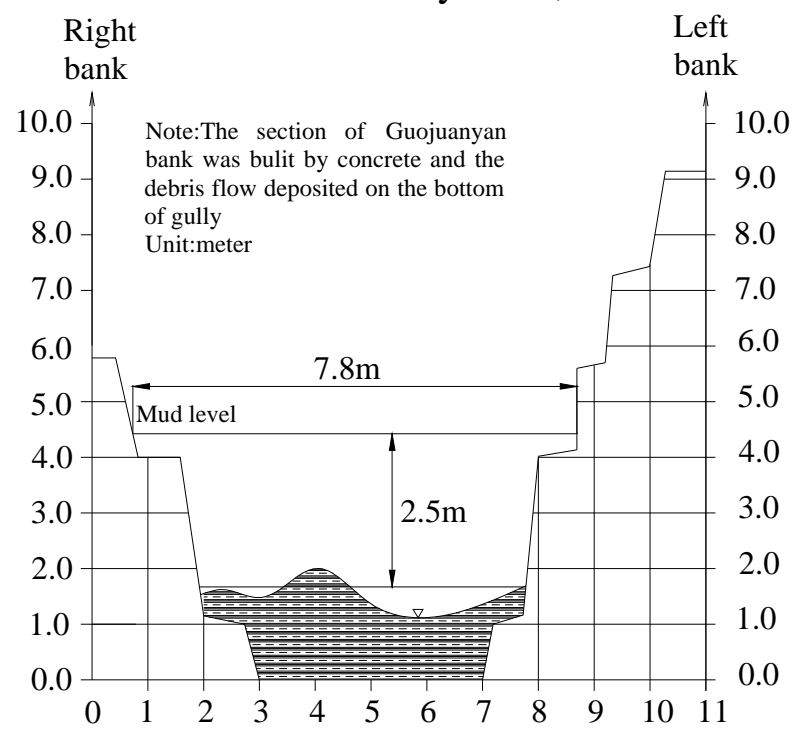

Fig.7 Schematic diagram of mud gauge observation profile

Table 1The cross-section parameters of '7.9' debris flow

\begin{tabular}{ccccc}
\hline The max width & Mean mud depth & The max section area & Hydraulic radius & Angle of slope \\
$\mathrm{B} / \mathrm{m}$ & $H_{C} / \mathrm{m}$ & $\mathrm{A} / \mathrm{m}^{2}$ & $R$ & $I_{C} / \%$ o \\
\hline 7.8 & 2.5 & 15.60 & 1.22 & 200 \\
\hline
\end{tabular}

Among it, the general velocity formula of viscous debris flow is

$$
u_{c}=M_{c} H_{c}^{2 / 3} I_{c}^{1 / 2}
$$

where $u_{c}$ is debris flow velocity $(\mathrm{m} / \mathrm{s}), M_{c}$ is debris flow roughness, it is set as $10, H_{c}$ is mean debris flow depth of calculating section(m), $I_{c}$ is angle of slope which is substituted by gully slope(\%o).

The average velocity formula of viscous debris flow is

$$
u_{c}=1.1(g R)^{1 / 2} I_{c}^{1 / 3}\left(D_{50} / D_{10}\right)^{2 / 3}
$$

where $u_{c}$ is viscous debris flow velocity $(\mathrm{m} / \mathrm{s}), g$ is gravity acceleration $\left(\mathrm{m} / \mathrm{s}^{2}\right), R$ is hydraulic 
radius(m), $I_{c}$ is angle of slope which is substituted by gully slope(\%), $D_{50}$ is particle size corresponding to the cumulative sand diameter percentage less than $50 \%(\mathrm{~mm}), D_{10}$ is particle size corresponding to the cumulative sand diameter percentage less than $10 \%(\mathrm{~mm})$. From Fig.6, it can attain that $D_{50}=1.5 \mathrm{~mm}, D_{10}=0.025 \mathrm{~mm}$.

The debris flow peak discharge $Q$ can be expressed as

$$
Q=A u_{c}
$$

Additionally, through rainfall process and video observation, it found that each debris flow showed a short during time(ca.40 min), the peak discharge appeared at the start of debris flow process. Thus, the total amount of debris flow calculation could be substituted by simplified hydrograph based on water balance theory[10], the formula can be expressed as (4) and the calculated results were shown inTable 2.

$$
V=0.2 t Q
$$

wheret is during time, min.

Table 2The dynamic value of ' 7.9 ' debris flow

\begin{tabular}{cccc}
\hline \multirow{2}{*}{ Formula } & $\begin{array}{l}\text { The Mean Velocity } \\
u /\left(\mathrm{m}^{-1} \mathrm{~s}^{-1}\right)\end{array}$ & $\begin{array}{l}\text { The Peak Discharge } \\
\mathrm{Q} /\left(\mathrm{m}^{3} \cdot \mathrm{s}^{-1}\right)\end{array}$ & $\begin{array}{l}\text { The Total Amount } \\
V / 10^{4} \mathrm{~m}^{3}\end{array}$ \\
\hline$(1)$ & 8.24 & 128.544 & 6.17 \\
$(2)$ & 6.41 & 99.996 & 4.80 \\
\hline
\end{tabular}

According to investigating the deposition out of gully mouth, it could be evaluated that the amount of deposition on the debris flow fan was ca. $3.7 \times 10^{4} \mathrm{~m}^{3}$, seeTable 3 , meanwhile, the left bank on the gully mouth and full swim pool was about $1.0 \times 10^{4} \mathrm{~m}^{3}$, and the ones carried out by flood was ca. $0.2 \times 10^{4} \mathrm{~m}^{3}$, therefore, the total deposition was ca. $4.9 \times 10^{4} \mathrm{~m}^{3}$. The results of formula (2) could reflect the actual phenomenon, that is, the debris flow velocity was $6.41 \mathrm{~m} / \mathrm{s}$, the peak flow discharge was $100.00 \mathrm{~m}^{3} / \mathrm{s}$. Similarly, due to the high flow velocity, a ramp turns supperelcvation was shown at the convex bank. Through investigating, a significant supperelcuationphenomenon show in the ' 7.9 ' debris flow, the height reached excel $2.0 \mathrm{~m}$ and the turned flow buried the left farmer building and the swimming pool which showed this debris flow possess high harmfulness characteristics.

Table 3The deposited fan parameters of ' 7.9 ' debris flow

\begin{tabular}{cccc}
\hline Length $/ \mathrm{m}$ & Width $/ \mathrm{m}$ & Angle $^{\circ}$ & Deposited Amount $/ 10^{4} \mathrm{~m}^{3}$ \\
\hline 82.0 & 105.0 & 6.0 & 3.7 \\
\hline
\end{tabular}

\section{Deposition Characteristics}

Through field survey, '7.9' debris flow resulted in deposition on the both bank foot and the fan of gully mouth. Most of solid source originated from the back of GJY, some transferred out of gully by mixture with water and a part of it deposited at the foot of slope and whole gully which provided the solid source condition for the next debris flow. While the gully fans deposition, abundant of sand, gravel and viscous materials flow out of gully mouth to form a debris flow fan which was the most serious disastrous area. The observation results of the deposition fan as Table 3.

The materials were mainly sand and gravel, some huge rocks distributed on the gully and deposition fans, with measuring, one of the big granite rock size reached $4.2 \mathrm{~m} \times 3.7 \mathrm{~m} \times 3.3 \mathrm{~m}$ which weight ca. 130 tons. To carry it out of the gully, local people shattering it by the way of dynamite explosion.

\section{Debris Flow'S Damage Feature}

'7.9' debris flow had two harm way as bury and impact. Through field survey, the mainly buried hazard positions were the farm building on the deposit fans and the country road of Hongkou-Longchi. While the impact hazards showed that the observation gauge, GJYBridge and electrical fracture out of gully mouth were hit seriously. Additionally, this debris flow rushed away 
many Magnolia officinalisRehd. etWils on the right bank of GJY gully.

\section{Debris Flow Activity and Development Tendency}

\section{Debris Flow Activity of GJY Gully}

Through investigation, it can get that there were none of debris flow events happened before Wenchuan Earthquake in the GJY gully except some different scale flood in the rainy season, which did not take menace for local villagers.

While Wenchuan Earthquake reduced abundant of loosen solid materials distributed on the surface of GJY watershed which provided abundant of solid source for debris flow, thus, debris flow had broken out during the heavy rainstorm in every rainy season after Wenchuan Earthquake. For instance, Shenxi gully happened large scale debris flow aroused by heavy rainstorm in the $13^{\text {rd }}$, Aug, 2010, which ruined the earthquake parkunder construction and some other state infrastructures, the village road was destroyed dozens of days. $1^{\text {st }}$, July, 2011, GJY gully had broken out debris flow after heavy rainfall, which ruined the check dam built by Administration of State Resource and serous destroyed the canal and village building. $7^{\text {th }}$, Aug, 2012, on the condition of previous rainfall, GJY happened debris flow and reduced the check dam base serous destroy. While on the $7^{\text {nd }}$, July, 2013, with previous rainfall and long during precipitation, debris flow block the canal, when another heavy rainfall process appeared in the next day, GJY gully broken out debris flow again, which buried the canal, farm building and destroyed the GJYbridge and power infrastructure once again. It was significantly concluded that high frequency of debris flow in GJY gully had broken out every year, see Table 4 .

Table 4The statistics of GJY debris flow events after earthquake

\begin{tabular}{cccccccccc}
\hline \multirow{2}{*}{ Time } & \multicolumn{2}{c}{2008} & & 2009 & \multicolumn{2}{c}{2010} & 2011 & 2012 & \multicolumn{2}{c}{2013} \\
\cline { 2 - 11 } & Before $12 / 5$ & $24 / 9$ & $17 / 7$ & $13 / 8$ & $18 / 8$ & $01 / 7$ & $17 / 8$ & $09 / 7$ & $26 / 7$ \\
\hline \multirow{2}{*}{ Debris flow } & None & $\mathrm{Y}$ & $\mathrm{Y}$ & $\mathrm{Y}$ & $\mathrm{Y}$ & $\mathrm{Y}$ & $\mathrm{Y}$ & $\mathrm{Y}$ & $\mathrm{Y}$ \\
\hline
\end{tabular}

\section{The Debris Flow Development Tendency of GJYGully}

With investigation, GJY gully had tremendous change post-earthquake, collapse and landslide body deposited on the formation area and both bank of gully which provided abundant of solid source in the small basin. From geomorphology, short and narrow gully which showed a typical ' $V$ ' shape, loosen solid materials had a fail tendency with hydrodynamic condition. Elsewhere, the debris flow development index $R[11]$ was calculated by watershed area, solid materials supplement areas, average angle of slope and some other factors, $R$ equal to 0.19 which mean that GJY gully belong to viscous debris flow so far and it was in developing stage currently. Therefore, it could attain that GJYgully has been transferred to debris flow gully from flood gully after Wenchuan Earthquake. A curtain scale debris flow would break out roused by continuous rainfall process in the future, till the back of GJY formation area possesses a curtain consolidation.

\section{Advices on GJY Debris Flow Prevention and Mitigation}

The heavy rainfall process in the Baisha region also resulted in some other debris flows as Wuxianmiao debris flow, red Gangou debris flow. Thus, with considering the loss and high frequency of debris flow in GJY gully, some advices were proposed as following.

(1) Popularize disaster prevention knowledge and strengthen the local people's disaster awareness

Disaster prevention experiences indicated that one possesses disaster awareness and skills could protect himself effectively. There are 5 villages distributed in the GJY gully and Shenxi gully, the total population excel more than 400[12]. Thus, it could disseminate by magazine, radio, booklet, panel board and disaster popular science lectures et al, raising local people's mountain hazard's awareness.

(2) Launch further mountain disaster detailed investigation and activity evaluation

Geo-environment, amount of disaster and the activity changed significantly of Hongkou region after Wenchuan Earthquake. The rainfall process along Mt LongmenFault resulted several mountain 
hazards in Shenxi gully watershed. Thus,local Administration needs to carry out detailed investigation to find out each disaster's distribution, activity, harmness and development tendency et al.Similarly, take effective evaluation on mountain disaster prevention engineering which built after earthquake, to provide basis for mountain planning and disaster prevention.

(3) Rational planning on mountain area and work on disaster management

According to the contradiction between people and land, rational choose and plan villagers land is very important, as to building, road, power infrastructure, earthquake park et al, it should take disaster prevention one by one on considering its significance. GJY check dam in the source area have been worked more than 2 years, the dam foundation eroded hardly and the dam storage capacity overloaded seriously, which need urgently to desilt or strengthen the check dam. Meanwhile, the curve at the gully mouth should change to straight which used to flow downward to Shenxi gully directly, rather than block Shenxi gully.

(4) Carry out mountain hazard monitoring and early warning work around the GJY gully

Strong earthquake resulted in soil structure and its characteristics changed violently, thus the critical precipitation to arouse debris flow decreased sharply after Wenchuan Earthquake, the debris flow have entered a long activity period[13]. On considering lots of disaster distributed in Hongkou region, even the whole Basha River watershed, the monitoring and early warning station cannot satisfy the disaster requirement in the remote rural country. Thus, Administration should carry out mountain hazard monitoring and early warning work, such as set up the net of rain gauge or precipitation radar, and then use sensors of GPS displacement, soil deformation, soil water content and pore water pressure to monitor the soil physical characteristics during the rainfall process, which announce public when it reached threshold value.

\section{Conclusions}

(1) Previous rainfall and heavy rainfall process resulted in '7.9'GJY debris flow. Through characteristics analysis, '7.9' debris flow possessed high viscous particle and high flow velocity which caused harmful disaster.

(2) With affected by Wenchuan Earthquake, GJY gully have been changed from general flood gully to debris flow gully already, the broken frequency and debris flow scale appeared an increasing tendency.

(3) GJY gully have been entering the developing stage of debris flow gully. Short and narrow gully show a typical ' $\mathrm{V}$ ' shape valley, sediment on the surface and both bank of gully possessed high possibility of failure under hydrodynamic condition, thus, in the next dozens of years, GJY gully would be face in high debris flow disaster.

(4) On considering the '7.9' debris flow, it should increase the disaster awareness of local people, take further mountain hazard detailed investigation and activity evaluation, rational planning on mountain area and work on disaster management, it also need to establish debris flow monitoring and early warning station to ensure local people's life and properties, even state infrastructure's safety.

\section{Acknowledgements}

This work was financed by theChina Geological Survey Project(Grant no: 12120113011000)andNational NatureScience Foundation of China (grant no: 41502330).

\section{References}

[1] Xu Q. The 13 August 2010 catastrophic debris flows in Sichuan province: characteristics, genetic mechanism and suggestions,Journal of Engineering Geology,Vol.18(5),2010, p.596-608(in Chinese).

[2] Yang S, Pan H L, Ou G Q, et al. Loosen solid materials discrimination at debris flow source 
area----take DujiangyanGuojuanyan gully as an example//2012 2nd International Conference on Remote Sensing, Environment and Transportation Engineering, Nanjing,2012,p.1579-1583.

[3] Chen W W, Zhang J K, Xiang Z Y, et al. Status and preliminary conservation program Ofearthquake ruins in the Shenxigou region Dujiangyan City,Dunhuang Research, Vol. 6(2010), p.46-53(in Chinese).

[4] Information on http://sc.sina.com.cn/news/m/2013-07-17/0630102529.html

[5] Sichuan Provincial Department of Water Resources \& Electric. Calculation manual of Sichuan Provence catchment storm flood. Chengdu: Sichuan Provincial Department of Water Resources,1984.

[6] Li S.D, Ren X S, Yue S Y, et al. Earthquake and debris flow activities, Research of Soil and Water Conservation, Vol. 8(2),2001, p. 26-27(in Chinese).

[7] Yang Z J, Qiao J P, Tian H L, et al.Study on rainfall-induced regional geohazards prediction following Wenchuan Earthquake, Journal of Sichuan University (Engineering Science Edition), Vol. 42 (S1),2010, p. 38-42(in Chinese).

[8] Ministry of Land and Resources of the People's Republic of ChinaDZ/T 0220-2006. (2006): Exploration specification of debris flow disaster prevention, Beijing:China Standard Press.

[9] Yu B, Yang Y H, Su Y C, et al.ResearchonthegiantdebrisflowhazardsinZhouqucounty, GansuprovinceonAugust7,2010,Journal of EngineeringGeology,Vol. 18(4), 2010,p. 437-444(in Chinese).

[10]Zhang J N,Ma Y, Zhang HH, et al.Study on earthquake debris flow in Dagan gully,Dujiangyan, Sichuan,Journal of Mountain Science, Vol.28(5), 2010,p.624-627(in Chinese).

[11]Institute of Mountain Hazards and Environment, Chinese Academy of Sciences. (2000):ZhongguoNishiliu, Beijing: The Commercial Press, p. 41-42.

[12]Wang J, Ou G Q, Yang S, et al.Study on hazard main-control factors in debris flow-prone areas after Wenchuan Earthquake based on CF method, Journal of Sichuan University (Engineering Science Edition), Vol. 45(S1),2013, p. 18-23(in Chinese).

[13]Cui P, Wei F Q, He S M, et al.Mountain disasters induced by the earthquake of May 12 in Wenchuan and the disasters mitigation, Journal of Mountain Science, Vol. 26(3),2008, p. 280-282 (in Chinese). 